\title{
The role of art education in adult prisons: the Western Australian experience
}

\begin{abstract}
Incarceration costs are high; in Australia, for example, each prisoner costs an average of $A \$ 115,000$ per year. Other countries are also feeling the fiscal pinch of high incarceration costs and some jurisdictions are now closing some of their prisons. Most prison costs are nondiscretionary (accommodation, meals, etc). Some of the costs relate to discretionary activities, services and facilities (including schooling). In relation to correctional education, prison managers will seek to invest scarce resources in those classes and courses that have the best outcomes such as reduced subsequent imprisonment. The questions this paper poses are: do art classes and courses produce these measurable outcomes and, if not, are there other reasons why they should continue to be funded? Our paper then argues that (1) these outcomes are too narrow and not reflective of the complex but less quantifiable benefits to the individual and the community of studying art in prison and (2) better measures of all impacts of art studies in prisons are needed.
\end{abstract}

Keywords: Art studies, correctional education, prisoners, welfare dependence, recidivism. 
"Art and Prison do not appear to have much in common. Art reflects creativity and freedom in expression, while Prison suggests a regimented environment surrounded by barbed wire. Art plays a central role ... helping inmates develop and cultivate their creative talents ... art can help ex-offenders unlock their potential in employment, education, and eventual reintegration into society." (see www.prisons.gov.sg)

\section{Introduction}

Incarceration costs are high; in Australia, each prisoner costs an average of $A \$ 115,000$ per year (2012/2013 figure from Australian National Council on Drugs, 2013). Most of these costs are non-discretionary; they pertain to minimum standards of accommodation, meals, custodial services and mandated drug, alcohol and rehabilitation programs. Some costs relate to what many prison managers consider as discretionary activities, services and facilities, such as gyms and swimming pools, libraries and chapels, and schooling. Often correctional education budgets stay fixed when prison numbers swell, and are the first to feel cutbacks. This means a declining proportion of the muster who can access education and longer class waiting lists. It also means that correctional authorities and prison managers will seek to invest scarce resources in those classes and courses that have the best outcomes - reduced re-offending behaviour and fewer subsequent imprisonments as well as sustained reintegration into their community which may or may not include finding and keeping paid work. The questions this paper poses are: do art classes and courses (rather than art therapy which is part of behaviour management programs) produce these good outcomes and, if not, are there other reasons why they should continue to be funded? 
The paper is organised as follows. Section 2 summarises literature on the purpose, practice and expected outcomes of correctional education generally and of art education specifically. Section 3 introduces the WA education and welfare dataset and the context of education and training courses and their accreditation in Australia. Section 4 presents the results of analyses of art class participation in adult prisons in WA and ex-prisoner outcomes in terms of two available measures of post-release success - re-imprisonment and welfare dependence. Key findings and future research are discussed in Sections 5 and 6.

\section{Literature review}

Studies of the purposes, practices and expected outcomes of correctional education are many and diverse. Few of these studies follow strict evaluation guidelines that dictate random allocation to control and intervention groups which have similar profiles. Other studies attempt to identify and correct for profile differences using post hoc propensity score matching, econometric techniques for correcting for different profiles (Blinder, 1973; Oaxaca, 1973), or Heckman's two stage procedure that uses the probability of sample inclusion to adjust parameter estimation (Heckman, 1979).

In the 1960s and early 1970s, the mainly US literature was ambivalent as to the effects of studying in prison. At the end of this period, a comprehensive and renowned study concluded that correctional education was unequivocally a waste of time and taxpayers' money “Nothing matters" (Martinson 1974). Since 1974, critiques of Martinson's study (such as Sarre, 1999), together with further primary studies into the effectiveness of correctional education (Nally, Lockwood, Knutson, \& Ho, 2012) and meta-analyses (Davis et al 2013) have reported that ex-prisoners who study tend to recidivate less (Anders \& Noblitt, 2011; Batchelder \& 
The role of art and art education in adult prisons

Pippert, 2002; Chavez \& Dawe, 2007; Kling \& Krueger, 2001; Lochner \& Moretti, 2004; Nally et al., 2012; Social Exclusion Unit, 2002; Steurer et al., 2001) and work more (Apel, 2014; Giles, Cooper and Jarvis, 2014). In addition, results are best for studies that incorporate vocational training (Giles and Le 2007). The intuition behind these results is that education increases the alternatives available to young people and raises the cost of time spent in prison (Lochner and Moretti, 2004) and education makes individuals less impatient and more risk averse (Riddell, 2006; Torre \& Wraith, 2012).

In most cases these studies used justice system data to examine recidivism and its link to prison study. Few studies had access to post-release employment information for ex-prisoners. However, in one such study (Nally et al., 2012) the authors collaborated with corrective services and workforce development public agencies to access post-release employment data (primarily occupation and income) related to a cohort of ex-prisoners, together with the prisoner/exprisoner demographic and offence information. These authors were therefore able to report on the links between in-prison study, and both recidivism and post-release employment.

A handful of studies found that the effect of correctional education on reduced reimprisonment was not necessarily because ex-prisoners had gained employment (Apel 2014; Giles, Cooper and Jarvis 2014). This finding is particularly important as studies looking only at post release labour market outcomes are finding little support for correctional education (Davis, et al. 2013). Most quantitative studies of the effectiveness of correctional education did not disaggregate the data beyond qualification level such as General Education Diploma (GED) in the United States (US) or Adult Basic Education (ABE) in Australia. Few studies examined classes in terms of discipline or course content (for example, economics or management), or skill set (such as 
metal work or carpentry). Djurichkovic (2011), at the conclusion of her paper which qualitatively appraised art programs in Australian prisons, petitioned for "quantitative evaluations of existing art programs ... would contribute important information about the value of prison art programs ..." (p. 29). However, such quantitative studies have yet to be found.

Nonetheless, qualitative research on the potential benefits of art education and art therapy in prison on prisoners and ex-prisoners finds that art creation enables learners to master skills, materials and techniques, to express abstract ideas and to become visually literate (Morgan 2014). These achievements can then lead to personal growth beyond competency and capability - increased civic and social awareness (Seidel, Tishman, Winner, Hetland, \& Palmer 2009) differentiation between self and others and between present and past selves (Bandura 2001), reduced negative patterns of thoughts and behaviours (Kaufman 2013) and increased self-esteem and self-worth (Bandura 2001). These outcomes may not lead directly to fewer offences or better labour market participation, but may lead to less easily quantifiable outcomes that auger well for better behaviour in prison and successful rehabilitation and reintegration outside prison. Gussak (2013), in his reflection of art therapy in prisons, states that "there seems to be a natural tendency for artistic and creative expression in prison settings ... evident in prison craft shops, murals, ... and of course intricately designed tattoos".

Seidel, Tishman, Winner, Hetland, and Palmer (2009), in their appraisal of art education in the classroom using interviews with arts education theorists practitioners and observations of arts progams, suggested that the experience of learning to create art can build civic and social awareness, enhance self-esteem, and reprogram otherwise habitually negative patterns of thought and behaviour. In addition, mastering art skills, materials and techniques can lead 
students, be they incarcerated or not, to conceptualising themselves, for the first time, as creative or special - characteristics that stand at odds with hitherto familiar notions of failure and worthlessness (Djurichkovic 2011). Furthermore, the richer quality of thinking resulting from art education pervades the kind of images and artworks produced (Eisner 2009).

In this paper, we take up Djurichkovic's (2011) suggestion to quantitatively appraise the effectiveness of prison art studies classes by analysing data from adult public prisons in Western Australia (WA) for prisoners and ex-prisoners who have completed one or more art classes during their imprisonment. In particular, we explore the recidivism and welfare dependence outcomes for these ex-prisoners using the WA prisoner education and welfare dataset (Giles and Whale, 2014). In the next section, this dataset and key parameters are described and the methodology for the data analysis is presented. In addition, the Australian

Qualifications Training Framework, as it applies to prison studies in WA, is summarised.

\section{Method}

The WA prisoner education and welfare dataset (Giles and Whale, 2014) contains de-identified records of 14,643 prisoners and ex-prisoners who were incarcerated in adult public prisons during the period 1 July 2005 to 30 June 2010. This dataset is compiled from records contained in two databases managed by the WA Department of Corrective Services (DCS) - the total offender management system (TOMS) and the correctional education enrolment and completion database known as Pathlore. Extracted and de-identified records from these databases were linked using a unique statistical linkage key based on family and given names, date of birth and gender. 
In the dataset, some prisoners had only one prison term recorded $(66 \%)$ and others had two or more prison terms (34\%). Due to the cut-off dates for the data extraction, the dataset precludes information about these prisoners for prison terms that ended prior to 1 July 2005 or started after 30 June 2010. In the absence of evidence to the contrary, it is assumed that the prisoner profile within the five years of data is a reasonable approximation to the prisoner profile generally. The dataset does not include information about prior schooling or work history. This information is collected via self-report during reception interviews with prisoners, usually for the purpose of developing learning plans (if prisoners are interested or their sentence terms require it), but this self-reported information is not encoded into either TOMS or Pathlore.

Study in adult prisons in WA is not a compulsory component of imprisonment or a mandated sentencing requirement; prisoners self-select into classes although they still need to meet prerequisites $^{2}$ and not be in breach of prison behaviour rules. Four in five prisoners enrol in at least one education or training class. Prisoner-students differ from other prisoners in terms of both socio-demographic characteristics and prison history characteristics. Proportionately more male prisoners study compared with female prisoners; those age 26 to 40 years are more likely to study; prisoners from non-metropolitan regions are more likely to study as are indigenous prisoners; and prisoners with longer prison sentences or more prison terms are more likely to enrol in classes. Thus there is some selection bias apparent in the profile of prisoners who choose to study.

In the dataset, four in five prisoners ( $n=11,781$ prisoners) had study records for 140,532 classes - about 12 classes per prisoner-student. Classes are units or modules within courses, most of which are accredited courses within the Australian Qualifications Training Framework 
(AQTF). These courses range from Certificate Courses to Diploma, Associate Degree or Bachelor degree courses. Certificate 1 courses typically contain four classes or modules, and undergraduate degrees 24 classes or units.

The AQTF was established in 1993 with a Vocational Education and Training (VET) focus for students seeking an industry based career. It provides for recognition of prior learning (RPL) as a result of industry experience in accreditation processes. Registered Training Organisations and Technical and Further Education (TAFE) service providers oversee the delivery, assessment and accreditation of these industry-aligned qualifications. DCS is licenced as an RTO which means that it can also deliver accredited and other training courses in prisons alongside other RTOs who are also contracted to deliver courses.

Certificate courses are framed around Training Packages (suites of small units aligned with post study employment opportunities) and are competency-based (students either demonstrate the requisite skills to pass the unit or repeat the assessments until such time as they are deemed competent). Certificate IV qualifications are deemed to be the equivalent of senior secondary school or university entrance courses and provide pathways for entry to tertiary (university) programs of study. Certificates I to IV in Visual Art and Contemporary Craft are an example of these certificate courses for which prisoner-students in Western Australian prisons can enrol. Diploma and Associate Degree courses are generally more conceptually oriented and content moves beyond foundation skills mastery (offered within the Certificate I to IV courses) to the development of advanced aesthetic sensitivities/visual literacy, high-end studio practice, complex critical analysis and personal response/personal voice. Degree programs are more advanced again and offer students an in-depth education in studio practice and art appreciation 
with the intent of training students to become visual artists or arts professionals. There is also scope for those wishing to enter the teaching profession as specialist art teachers (often through a Graduate Diploma pathway) to continue their studies in initial teacher education programs after the completion of an undergraduate degree.

The curricula for these art studies classes depends on the accredited courses they belong to, but often the delivery depends on the prisoner-students who enrol in the classes - their prior learning and learning experiences, their ethnicity and age, and their interests. In addition, and unlike classes in most other courses, prisoner-students can re-enrol in the same class or unit many times as they develop their engagement with learning and gradually acquire the techniques and competencies expected for the class. Enrolment in a class usually covers one term (about ten weeks) of study although more time is often needed, especially for those prisoners with severe education deficits. Of prisoners who studied, $15 \%$ had enrolled in at least one art studies class.

The prison art teachers in Western Australia may be professional artists with a Certificate IV in Training and Assessment (the minimum requirement for teaching in Western Australia) or they may be university-trained with either a four year teaching degree with an art studies specialisation or a three year undergraduate degree in art studies with a one year diploma of education. These teachers collaborate with other teachers in the prison education centres in that they are part of a team of vocational and adult basic education (ABE) teaching staff. All teachers in prisons work together on assessment validation and moderation generally. They also coordinate timetables for individual prisoner-students in line with each prisoner's Individual Management Plan (IMPs). The art teachers also provide educational counselling for 
their prisoner-students, often recommending other studies, such as literacy classes, to prisoners who demonstrate a particular need. Conversely, the art teachers may also enrol students in their art studies classes following referrals of prisoner-students (for example, those with learning disabilities or very low levels of literacy) from other staff. Anecdotal evidence suggests that art studies classes for prisoner-students are sometimes used as a gateway to more formal study or vocational training and that the emphasis in the curriculum is more about becoming comfortable in the classroom and less about styles of painting, pottery and screen printing. In Western Australia, this is particularly true for prisoner-students who grew up in regional and remote Aboriginal communities.

In Western Australia, one of the previous working prisons, Fremantle Prison was classified by the National Trust of Australia (WA) in the 1980s and as a World Heritage site in 2010. This prison was decommissioned in 1991 and is now managed by the WA Department of Housing and Works who outsource its use as a tourist attraction complete with museum and art gallery spaces. DCS has an ongoing relationship with Fremantle Prison including exclusive use of gallery space for the exhibition of prisoner artwork. DCS holds four exhibitions per year in this space and prisoners are eligible to exhibit and sell their artwork. This work may have been undertaken either as part of either art studies courses or art therapy programs in prison.

Prisoners with artwork developed in their art studies or art therapy classes can also participate in exhibitions that are held on site. For example, during National Aborigines and Islanders Day Observance Committee (NAIDOC) week, art exhibitions may be held in the Visits areas or Education Centres of prisons. Other exhibitions may be organised through particular educational institutions such as the Curtin Graduate Exhibition. Other art exhibitions may be 
held in the community with the approval of the Deputy Commissioner (such as local council exhibitions and art awards). Art exhibitions held outside the prisons are generally curated with work available for sale. Some exhibitions may include awards or prizes which prisoners are eligible to win or may otherwise receive feedback. Art galleries in Western Australia are not directly involved in the delivery of content in art studies or art therapy programs.

In the quantitative analysis reported in the next section, the data are examined from two perspectives - (1) prisoners (who study at any time in their prison term(s)) and (2) the classes in which they enrol. The analysis, unless otherwise stated, includes all classes in which prisoners were enrolled at any time during their prison term(s). Two sets of descriptive statistics are provided. First, comparisons are made between the profiles and outcomes of studying prisoners who enrolled in at least one art studies ${ }^{1}$ class and those who did not enrol in any art studies classes. Second, art class enrolments are compared with non-art class enrolments. Chi square tests of statistical significance were used to test the differences between characteristics of prisoner-students who studied art and those who did not, and between enrolments in art studies classes and other classes.

Stata version 13 (StataCorp. 2011) was used to manage the dataset and conduct the statistical analyses. Ethics approval was obtained from the Research and Evaluation Committee of the WA Department of Corrective Services (September 2010) and the Faculty of Business and Law Ethics Sub-committee at Edith Cowan University (May 2011).

\section{Results}

The results are presented firstly in terms of prisoner profiles and then in terms of art studies course and class profiles. The content labels for these courses and classes includes the terms 
The role of art and art education in adult prisons

'art', 'art and craft', 'art and design', 'graphic arts', or 'visual arts'. Some of the analyses are conducted across all prison terms; other analyses only include the most recent prison term.

The profiles of prisoner-students presented in Table 1 show those who enrolled in at least one art studies class ( $n=1,715)$ and those who enrolled in non-art studies classes $(n=10,066)$.

Prisoners could have enrolled in these classes in any prison term. Socio-demographic characteristics are shown in the top half of the table and prison term characteristics in the bottom half of the table.

(Insert Table 1 here)

Overall, $15 \%$ of prisoners enrolled in at least one art studies class. Proportionately more female prisoners studied art compared with male prisoners ( $23 \%$ compared with $13 \% ; \chi^{2}=93.4770, p<$ 0.01). This may be due to a more limited curriculum available to female prisoners during the data period rather than reflecting gender preferences. Mid-aged prisoners who chose to study were more likely to enrol in art studies classes compared with both younger and older age groups ( $16 \%$ compared with $13 \%$ and $14 \%$, respectively; $\left.\chi^{2}=12.4031, p<0.001\right)$.

Studying prisoners who last resided in rural WA were more likely to have enrolled in art studies classes (18\%) compared with prisoners who last resided in metropolitan WA (12\%) or outside WA (10\%) $\left(\chi^{2}=76.0117, \mathrm{p}<0.001\right)$. Aboriginal and Torres Strait Islander prisoners who studied were twice as likely to choose art studies classes (21\%) compared with non-Aboriginal and Torres Strait Islander prisoners $\left(\chi^{2}=274.5497, p<0.001\right)$. If art class enrolments reflect prior weak schooling and studying art is a pathway into formal education and vocational training, then the results for rural and Aboriginal prisoner-students are not surprising. School completion 
and attendance is generally poorer amongst rural students as it is for Aboriginal and Torres Strait Islander students.

Prisoners who undertook education and training classes and had more than one prison term and/or longer sentences were more likely to have enrolled in at least one art studies class. One in five prisoners with three or more prison terms enrolled in art studies classes compared with one in nine prisoners with only one term $\left(\chi^{2}=109.866, p<0.001\right)$, as did $27 \%$ of those serving more than five years compared with $8 \%$ of those serving up to one year $\left(\chi^{2}=347.4206\right.$, $p<0.001)$. These results are intuitively appealing. First, prisoners with longer sentences and/or more prison terms often have more serious offences. Secondly, having more time in prison through either longer sentences or more prison terms means that interested prisoners are able to enrol in more classes from a wider selection of courses.

Class enrolments are only one part of the education picture for prisoner-students. The more important aspect is whether or not these classes are successfully completed - necessary competencies met (for short courses and vocational studies) or pass grades achieved (for adult education or university studies). Alternatively, classes may be repeated or incomplete.

In prison, classes may be repeated if class curriculums have changed and progress through the course has been too slow. For example, a prisoner may start a training course during one prison term and want to continue enrolment in that course during a subsequent prison term. If the class content has changed, then they will need to repeat the class even if they have previously successfully completed it. This is an endemic problem with vocational education and training in Australia due to persistent changes in competencies required for many trades. 
Prisoners may withdraw from classes (two thirds of incomplete classes are due to withdrawal) for a variety of reasons, most commonly, transfer to other prisons, changes in individual management plans, early release to freedom (one third of incomplete classes are due to prisoners leaving prison) or escape. Prisoners might also incur infringements for offences committed in prison with penalties including removal of access to education and training. Occasionally prisoners might be required as part of their sentencing to undertake programs such as drug rehabilitation and anger management, when places become available, these will take precedence over education and training. Finally, some prisoner-students may not have achieved the required level of competency for the class although this is rare, applying to less that $1 \%$ of incomplete classes.

(Insert Figure 1 here)

Figure 1 compares class outcomes - successfully completed, repeated, incomplete - for art studies and non-art studies classes. Only $4 \%(n=5,531)$ of the 140,532 classes in which prisoners are enrolled qualify as 'art studies' classes. Proportionately fewer art classes were successfully completed (41\%) compared with non-art classes $(62 \%)\left(\chi^{2}=1039.4907, p<0.001\right)$; proportionately fewer were repeated ( $1 \%$ compared with $4 \% ; \chi^{2}=100.9128, p<0.001$ ); and proportionately more were incomplete $\left(58 \%\right.$ compared with $34 \% ; \chi^{2}=1343.4414, p<0.001$ ). Prisoners who study art may also be enrolled in classes in other subjects either concurrently or subsequent to their art classes. The data show that $71 \%$ of prisoners whose first class in their most recent (or only) term is an art class enrol later in other classes - only art classes (4\%), art and vocational classes (28\%), only vocational classes (20\%) and other classes such as tertiary 
study (19\%). For prisoners whose first class in their most recent term is not an art class, these proportions are less than $1 \%, 6 \%, 47 \%$ and $22 \%$, respectively. Thus prisoners whose entry to study starts with at least one art class continue to study art, whereas if they enrol in non-art classes at the beginning of their prison term, they are unlikely to add art classes to their study program at a later time.

To examine study pathways more closely, it is worth examining non-art class enrolments in terms of whether or not they include subjects within adult basic education (ABE) courses. These courses, which include General Education for Adults, Entry to General Education and Introduction to General Education for Adult Learners ${ }^{3}$, are intended to backfill education deficits to minimum schooling levels. In Western Australia, ten years of schooling is compulsory although not all students who complete year ten have met the necessary achievement benchmarks due to truancy, ill-health and learning disorders, for example. Students in remote areas may also be subject to school closures due to floods and other weather events that prevent them from travelling to their local school. Table 2 summarises combinations of art and ABE classes for prisoners who studied in their most recent (or only) prison term.

(Insert Table 2 here)

Thus, $74 \%$ of prisoners who studied art also enrolled in ABE classes in their most recent term compared with $61 \%$ of prisoners who enrolled in $A B E$ classes but did not enrol in any art classes. Moreover, one quarter of prisoner-students who enrolled in art classes also enrolled in other classes that did not include ABE classes; for those who did not study any art, $40 \%$ did not (need to) enrol in ABE classes $\left(\chi^{2}=80.462, \mathrm{p}<0.001\right)$. These results provide further evidence 
that art studies appear to be the start of a pathway into further study which, for prisoners with the poorest educational history, means enrolling in classes that will enable them to firstly complete a base level of schooling.

Of interest to prison authorities, and ultimately the community, is whether or not study in prison can turn lives around. Two traditional measures of the 'success' of prison education and training programs are improved labour market outcomes defined in terms of workforce participation, employment and occupation, and reduced recidivism.

The labour market measures of participation, employment and occupation are not directly available within the WA prisoner education and welfare dataset. However, this dataset does include information on welfare dependence - type of welfare payments and dates of entry and exit into payments. For the purpose of practically analysing reliance on income support, it is assumed that ex-prisoners are not available for work or job search during the time period from day one to four months post release. This assumption is based on anecdotal evidence from prison authorities, community corrections staff and job search agency staff regarding the process that ex-prisoners need to go through when first they exit prison. Connecting back with family and community, contacting parole officers, signing up to Centrelink ${ }^{7}$ and job service providers, attending proscribed rehabilitation programs, and finding housing and transportation are important, necessary and time-consuming actions. Ex-prisoners also need to learn how to live in a less regimented way, choosing what to wear and when to eat, etc.

Note that for female prisoners and Aboriginal and Torres Strait Islander prisoners looking for work and accessing income support is complicated. For female ex-prisoners, care responsibilities tend to take precedence over finding paid work and coming off welfare. For this 
group then, income support is likely to continue. Aboriginal ex-prisoners from rural and remote WA were unlikely to receive income support if their communities were supported via the Community Development Employment Program (CDEP) (see http://www.dss.gov.au/ourresponsibilities/indigenous-australians/programs-services/communities-regions/communitydevelopment-employment-projects-cdep-program ). This program (recently withdrawn) provided welfare funds to the community to distribute rather than to individuals, and the funds supported labour and other input costs of community infrastructure and other projects.

Analysis of welfare data suggests that time needed for this adjustment to living on the outside is, on average, four months (Giles and Whale 2015). The time duration for ex-prisoners to receive unemployment benefits (or student allowance ${ }^{4}$ ) can then be measured using 4 months post release as the start of a period in which ex-prisoners could be available to join the labour market. Table 3 presents a summary of welfare dependence, defined in this way, in terms of type of prison studies.

(Insert Table 3 here)

Column 2 of Table 3 shows that ex-prisoners who were enrolled in at least one art class during their most recent prison term remain on unemployment benefits for one third of their period of availability (20 out of 62 days). Ex-prisoners who were enrolled in non-art subjects during their most recent term exit welfare within 6 days. To some extent the longer time on benefits for prisoners who study art reflects their longer prison terms or recidivism. These contribute to gaps in resumes which compromise their employability. 
The second measure of the 'success' of prison education and training programs is reduced recidivism. Two definitions of recidivism are used here. First, recidivism is defined as reincarceration within three years of release. This is in line with the meta-analysis of the contribution of prison education and training to reduced recidivism by Davis et al. (2013). Table 4 shows the proportion of ex-prisoners who recidivate using the subsample of studying prisoners who were released prior to 30 June $2007^{6}$. For example, a prisoner who started their sentence on 1 July 2005, was released on 30 March 2007 and had no further imprisonment recorded in the dataset would be recorded as 'not a recidivist'. Another prisoner who was imprisoned several times before 30 June 2007, was released from the last prison term on 30 March 2007 and was re-incarcerated on 30 September 2008 would be recorded as 'a recidivist'. The most recent or only prison term is considered and the sample size is 3,650 . The overall recidivism rate is $51 \%$.

(Insert Table 4 here)

Table 4 shows that the rate of re-incarceration for studying prisoners who had enrolled in at least one art class is higher (56\%) than for those who enrolled in non-art subjects (51\%). This difference is statistically significant at the $10 \%$ level $\left(\chi^{2}=3.507, p<0.10\right)$. As mentioned earlier, if years of schooling and propensity to offend are correlated and prisoners with poorer education histories enrol initially in art classes, then this result is to be expected.

(Insert Table 5 here)

A second definition of recidivism is reduced time in the community between consecutive sentences. Here the sample size is 1,230 and the subsample is those studying prisoners with 
more than two prison terms. Results presented in Table 5 are that studying prisoners who enrolled in at least one art studies class were more likely to have escalating criminal behaviour (44\%) compared with those who enrol in non-art subjects (43\%). However, this difference is not statistically significant.

The quantitative analysis presented here provides a preliminary investigation into the merits of art studies in prison. The findings can be used as a starting point to further more detailed qualitative analysis to specifically examine art studies curricula as well as art teacher delivery styles. The combinations of art studies and other studies are also worth a closer look as the data suggest that pathways that include art studies (particularly as an entry point to education and training in prison) are important for some prisoner-students.

\section{Discussion}

The data unequivocally show that prisoners who enrol in at least one art class have poorer post release outcomes in terms of re-offending behaviour and work readiness than prisoners who do not study art. That is, their rate of recidivism is higher and their unemployment rate appears also to be higher. Before looking at the bigger picture of art instruction in prisons, it is worth examining more closely these two measurable outcomes.

First, whilst prisoner-students engaging in art studies may experience a range of benefits from educational advancement to personal growth, their release from prison itself and their inability post release to continue or progress their art may contribute to re-offending behaviours. Importantly, the absence of continued participation in art studies after prison could be truncating the momentum for positive change underway during their incarceration. Hence, continuing participation in art studies classes through community based support programs, may 
be a connective thread to the positive change begun in prison. One example of a successful program of this type already exists in the form of the JETA program offered by Curtin University in Western Australia (see http://humanities.curtin.edu.au/schools/DA/art/jeta.cfm ).

Next, the slower exit from income support for ex-prisoners who participated in art studies classes in prison may be because these studies are less vocationally oriented and less likely to promote the development of employability skills such as working in teams and managing timed tasks. Studies of university or vocational college art graduates also show a similar trend. That is, paid work as 'an artist' is not as forthcoming as employment as 'an accountant' or 'a bricklayer'. It is therefore not unexpected that graduates of prison art courses also have difficulty finding paid work in their field. The result might also reflect that these prisoners may have a bigger education deficit so that their entry to the world of paid work is already compromised.

The data also show that art studies in combination with other courses might mitigate these seemingly poor outcomes. Moreover, it is most likely that art studies in prison serve a different and less quantifiable purpose. The more relaxed classroom experience and literacy and numeracy prerequisites (Djurichkovich 2011) and the opportunity to be artistically creative provide these incarcerated students - who have poor prior schooling - a more gentle entry to education and training than desk-based subjects or on-the-job workshop-based learning. The required competency for their artwork can be achieved irrespective of how traditional, different or edgy it is. This becomes the start of the prisoner-students' journeys to self-efficacy; providing the encouragement needed to tackle other education and training opportunities. A point should be made here about prior schooling and how, for most prisoners, attending classes is an anathema. Recent research into learning disorders in prisons shows that $30-60 \%$ of 
prisoners have Attention Deficit Hyperactivity Disorder (ADHD) (see

http://www.epea.org/index.php?id=178; Asbjornsen 2015). Such disorders can contribute to truancy and early school drop-out rates but may go undiagnosed and untreated. The accompanying poor schooling experience can result in difficulty adjusting to traditional classroom teaching and learning delivery.

The results of the analysis of the WA data also reveal some interesting aspects of the study experiences of prisoners, in particular whether or not they choose to enrol in art studies classes and, if they do, whether they successfully complete these at their first attempt or any attempt. Looking firstly at the issue of enrolment, the increasing frequency with which recidivists elect to study art in prison suggests that the longer an individual is incarcerated, the greater is their desire for experiences aligned with themes in the literature, specifically self-esteem enhancement, increasing capability, and a sense of belonging and connection to others.

In terms of successful completion or not of their art studies classes, the findings are complicated. Incomplete classes are sometimes due to prison or sentence management imposts and sometimes to prisoner choices. It is possible that the need for consonance with established notions of self-worthlessness plausibly explains higher unsuccessful exit trends for prisoner-students who studied art. That is, prisoners behave in a manner that initially reinforces negative pre-existing belief systems before a delayed transition to behaviour modification (Tavris \& Aronson 2007). For example, the prisoner may believe: 'I am worthless'; therefore 'I am no good at anything'; therefore 'I will fail at anything I try; therefore 'I will fail at art'; therefore 'there is no reason to try'; therefore 'I will drop out of art' thereby, ensuring failure and consonance with the pre-existing identity construction of worthlessness. Cognitive 
dissonance and challenges to the pre-existing belief systems may take time to develop; over a long prison sentence or over consecutive prison terms.

For the participants in our study with sufficient time and/or sustained study experience, an education pathway encompassing Certificate I to IV studies, followed by diploma/advanced diploma course options, and culminating in an undergraduate degree program (with an arts studies focus) is possible. In post-prison settings, this type of scaffolded arts studies educational background not only offers a range of diverse employment options and continuing education opportunities it may also offer a transformational experience. In the best circumstances, as students move from unskilled novices to highly capable visual arts practitioners, there can be an attendant and inevitable reframing of self-identity as a result of increasing self-efficacy as a visual arts professional. Positive pathways to sustained post-release reintegration are then more likely.

\section{Future research}

The data on post incarceration outcomes considered in this study do not in and of themselves provide support for the expansion of art studies in prison, however, the wider research about art making, art education and art therapy does. For prisoner-students, challenged by their prior poor schooling and by the environment of their imprisonment, art studies classes may unlock the potential stumbling blocks to personal transformation and successful community reintegration. However, it is unclear from the aggregate data what types of art classes are most beneficial and whether correctional educators should put more effort to ensuring that prisonerstudents complete their classes successfully within AQF-accredited courses. Future research that collects qualitative data from prisoner-students and their teachers could shed light on the 
relative importance of different learning methods for art studies prisoner-students and different teaching approaches for the art studies teachers.

In addition, future quantitative evaluations of art studies programs in prisons should ensure that data on the content and delivery of art studies classes can be disaggregated and the impact of teacher quality - thought to be a key ingredient in schooling success (Klein et al., 2010) - is included. Further to this, initiatives in which universities (and particularly teacher-education pre-service training providers) partner with correctional institutions through art studies programs (like JETA), Artist in Residence Programs, or teaching practicum placements present as valuable opportunities for both stakeholder groups. The creative network established through such initiatives may offer prisoners access to expert artists during the period of their incarceration and direct links to external art programs and networks after their release. Reciprocally, the experience of teaching art in prison during the final period of pre-service training may contribute to the development of better art teachers through exposure to a broader framework of inclusivity and diversity needs. Finally, professional development for correctional educators should include information about the use of art appreciation, art making and art therapy for art studies classes specifically as well as across the curriculum.

\section{Notes}

1 Art classes that are part of behaviour therapy programs are not considered here.

$2 \quad$ Class availability may impact on enrolment at any one time.

3 Equivalent to General Education Diploma (GED) in the US.

4 From 1998, ABS did not differentiate between recipients aged 25 years and under who were seeking work or those who were enrolled in education.

5 This assumption removes the confounding effects of cyclical unemployment. 
6 A subset of the WA prisoner education and welfare dataset is required for this analysis which needs at least three years of post-release time to derive the re-incarceration measure.

7 The national welfare agency http://www.humanservices.gov.au/customer/dhs/centrelink

\section{References}

Anders, A. D., \& Noblitt, G. W. (2011). Understanding Effective Higher Education Programs in Prisons: Considerations from the Incarcerated Individuals Program in North Carolina. The Journal of Correctional Education, 62(2), 7-23.

Apel, R. (2014). Transitional Work Programs for Ex-Prisoners. Encyclopedia of Criminology and Criminal Justice, 5282-5289.

Asbjornsen, A.E., Manger, T. and Eikeland, O.-J. (2015). Symptoms of ADHD are related to education and work experience among incarcerated adults. Journal of Prison Education and Re-entry, 2(1), 18-30.

Australian National Council on Drugs (2013). An economic analysis for Aboriginal and Torres Strait Islander offenders: prison vs residential treatment. ANCD Research Paper 24. Canberra, ACT: National Indigenous Drug and Alcohol Committee.

Australian Qualifications Framework Council for the Ministerial Council for Tertiary Education and Employment. (2011). Australian Qualifications Framework 2011 (First Edition).

Bandura, A. (2001). Social cognitive theory: An agentic perspective. Annual Review of Psychology, 52(1), 1-26. 
The role of art and art education in adult prisons

Batchelder, J. S., \& Pippert, J. M. (2002). Hard time or idle time: Factors affecting inmate choices between participation in prison work and education programs. The Prison Journal, 82(2), 269-280. doi: 10.1177/003288550208200206

Blinder, A.S. (1973). Wage Discrimination: Reduced Form and Structural Variables. Journal of Human Resources, 8, 436-455.

Chavez, R., \& Dawe, S. (2007). International Research and Trends in Education and Training Provision in Correctional Settings. In S. Dawes (Ed.), Vocational Education and Training for Adult Prisoners and Offenders in Australia: Research Readings. Adelaide: National Centre for Vocational Education Research (NCVER), 19-33.

Djurichkovic, A. (2011). 'Art in prisons': A literature review of the philosophies and impacts of visual arts programs for correctional populations. Available at: https://epress.lib.uts.edu.au/research/bitstream/handle/10453/19836/ArtinPrisons Di urichkovic.pdf?sequence=3

Eisner, E. (2009) Vanderbilt Address: What do the Arts Teach. Available at: https://www.google.com.au/\#q=eisner+vanderbilt+address

Giles, M., Cooper, T. and Jarvis, J. (2014). Evaluation of Industry Skills Centre Program Victoria Prisons: Final Report. Unpublished report to Corrections Victoria, 4 December.

Giles, M. and Le, A.T. (2007). Prisoners' Labour Market History and Aspirations: A Focus on Western Australia, Economic Record, 83(260): 31 - 45. 
The role of art and art education in adult prisons

Giles, M. and Whale, J. (2014). Characteristics of prisoner education and training and welfare dependence: Western Australia. Phase 2 Report. Joondalup, WA: Centre for Innovative Practice, Faculty of Business and Law, Edith Cowan University.

Giles, M. and Whale, J. (2015). Redefining and analysing welfare dependence for ex-prisoners. Report to Faculty of Business and Law Research and Higher Degrees Committee. Joondalup, WA: Social Program Innovation, Research and Evaluation (SPIRE) Group, Edith Cowan University.

Gussak, D. (2013). Art Behind Bars. Psychology Today, 22 October. Available at: https://www.psychologytoday.com/blog/art-trial/201310/art-behind-bars

Heckman, J.J. (1979). Sample Selection Bias as a Specification Error. Econometrica, 47(1) 153161.

Kaufman, S. (2013). The real neuroscience of creativity. Available at: http://blogs.scientificamerican.com/beautiful-minds/

Klein, J.I., Lomax, M. and Murguía, M. (2010). Why great teachers matter to low-income students. The Washington Post. Friday, April 9. Available at: http://www.washingtonpost.com/wpdyn/content/article/2010/04/08/AR2010040804802.htm

Kling, J. R., \& Krueger, A. B. (2001). Costs, Benefits and Distributional Consequences of Inmate Labor, Working Paper No. 449. Princeton, NJ: Princeton University Industrial Relations Section. 
The role of art and art education in adult prisons

Lochner, L., \& Moretti, E. (2004). The Effect of Education on Crime: Evidence from Prison Inmates, Arrests, and Self Reports. American Economic Review, 94, 155-189. doi: $10.1257 / 000282804322970751$

Martinson, R. (1974). What Works? - Questions and Answers About Prison Reform. The Public Interest, Spring, 22-54.

Morgan, E. (2014). Creating Better: From rehabilitating offenders to assisting the disabled, art has a crucial role to play in WA's community services. Scoop Magazine. 68(Winter).

Nally, J., Lockwood, S., Knutson, K., \& Ho, T. (2012). An Evaluation of the Effect of Correctional Education Programs on Post-Release Recidivism and Employment: An Empirical Study in Indiana. The Journal of Correctional Education, 63(1), 69-88.

Oaxaca, R. (1973). Male-Female Wage Differentials in Urban Labor Markets. International Economic Review, 14(3), 693-709.

Riddell, W.C. (2006). The Impact of Education on Economic and Social Outcomes: An Overview of Recent Advances in Economics. Canadian Policy Research Networks Inc.

Sarre, R. (1999). Beyond 'What Works?' A 25 Year Jubilee Retrospective of Robert Martinson. Paper presented at the History of Crime, Policing and Punishment Conference convened by the Australian Institute of Criminology in conjunction with Charles Sturt University, Canberra, 9-10 December.

Seidel, S., Tishman, S., Winner, E., Hetland, L., Palmer, P. ( 2009). Understanding excellence in art education. Available at: http://www.wallacefoundation.org/knowledge-center/arts- 
The role of art and art education in adult prisons

education/arts-classroom-instruction/Documents/Understanding-Excellence-in-Arts-

Education.pdf

Social Exclusion Unit. (2002). Reducing re-offending by ex-prisoners. Retrieved from http://www.gos.gov.uk/497296/docs/219643/431872/468960/SEU Report.pdf

Steurer, S. J., Smith, L., \& Tracy, A. (2001). (report submitted to US Office of Correctional Education) Retrieved from http://www.criminologycenter.fsu.edu/p/nationalDataClearinghouse/Publications\%20R eports/OCE-CEA\%20-\%203 State Study.pdf

StataCorp. 2011. Stata Statistical Software: Release 12. College Station, TX: StataCorp LP.

Tavris, C. \& Aronson, E. (2007). Mistakes were made (but not by me): foolish beliefs, bad decisions and hurtful acts. Wales: Pinter \& Martin.

Torre, A. and Wraith, D. (2012). Some Empirical Evidence on Offender Time Discount Rates. Economic Papers, 31(2), 192-201. 